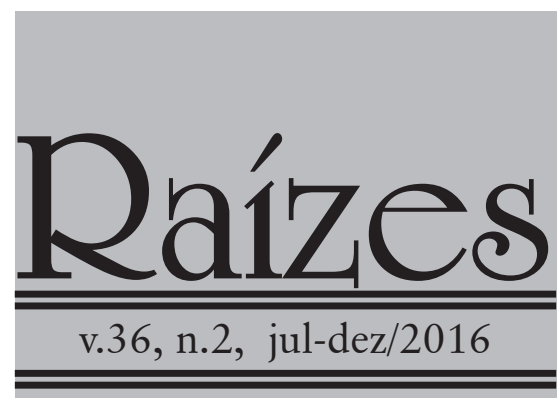

\title{
ASPECTOS INOVATIVOS PRESENTES NAS ATUAIS POLÍTICAS PÚBLICAS DE AQUISIÇÃO DE ALIMENTOS DA AGRICULTURA FAMILIAR BRASILEIRA
}

\author{
José Roberto Rambo, Silvia Maria de Almeida Lima Costa, Gilmar Laforga \\ RESUMO
}

O objetivo deste trabalho é demonstrar o caráter inovativo das políticas públicas voltadas à aquisição de alimentos da agricultura familiar brasileira. Ao criar alternativas para melhorar duplamente os níveis de eficácia, seja na busca de segurança alimentar (de ordem quantitativa com foco na contenção da fome), seja no desenho de novos mecanismos de mercado intermediados por organizações públicas, o Brasil inova ao formatar um ambiente institucional efetivamente capaz de criar incentivos para captura de valor dos produtos alimentícios produzidos pela agricultura familiar, aliada com uma estratégia de combate à fome, o que não ocorreria nos equipamentos de comercialização dos canais tradicionais de distribuição. Utilizando-se de recorte teórico de abordagem Neo-Schumpteriana, são discutidos alguns condicionantes relativos ao alcance das políticas em tela, quais sejam: o Programa de Aquisição de Alimentos da Agricultura Familiar - PAA, o Programa Nacional de Alimentação Escolar - PNAE e o Programa Paulista da Agricultura de Interesse Social - PPAIS (operante no Estado de São Paulo). As inovações de modelo de negócios geradas institucionalmente conferem maior alcance para o PAA e exigem maiores ajustes adaptativos para os outros dois programas no alcance dos objetivos expressos, remetendo à necessidade de revisões nos mecanismos de coordenação entre os atores sociais envolvidos.

Palavras-Chave: PAA; PNAE; PPAIS.

\section{INNOVATIVE ASPECTS IN CURRENT PUBLIC POLICIES OF FOOD PROCUREMENT OF BRAZILIAN FAMILY FARMING}

\section{ABSTRACT}

The aim of this article is to demonstrate the innovative aspects involved in current public policies for food acquisition of the Brazilian family farming. Creating alternatives to improve performance standards, in both, food security (of quantitative order focusing on hunger containment), and the design of new market mechanisms mediated by public organizations, Brazil innovates determining an institutional environment, effectively able to create incentives for a quality capture of the food products, produced by family farmers, which would not occur in the sale of equipment of traditional distribution channels. Using a theoretical cut based in industrial organization and Neo-Schumpterian approach, some constraints are discussed on the extent of the screen policies, namely: the Food Acquisition Program of Family Farming - PAA, the National School Feeding Program - PNAE and the Paulista Program Social Interest Agriculture - PPAIS (operating in the State of São Paulo). The business model innovations, institutionally created, provide greater scope for the PAA and require major adjustments to the other two programs in achieving the stated objectives, referring to the need to review the coordination mechanisms between the social participants involved.

Keywords: PAA; PNAE; PPAIS.

Professor Adjunto da Universidade do Estado de Mato Grosso (UNEMAT), Campus Universitário de Tangará da Serra-MT. E-mail: jr.rambo@unemat.br.

Professora Doutora da Universidade Estadual Paulista (UNESP), Faculdade de Engenharia de Ilha Solteira, Campus de Ilha Solteira-SP. E-mail: smalcost@agr.feis.unesp.br.

Professor Adjunto da Universidade do Estado de Mato Grosso (UNEMAT), Campus Universitário de Tangará da Serra-MT. E-mail: gilmar.laforga@gmail.com. 


\section{INTRODUÇÃO}

O Brasil vivenciou na última década uma série de transformações importantes relacionadas à construção de políticas públicas voltadas à agricultura familiar (SCHMITT; GRISA, 2013) ${ }^{1}$. Nesse sentido, a construção de mercados institucionais para esse setor produtivo ganhou espaço na agenda das políticas públicas de desenvolvimento rural especialmente a partir de 2003. Isso se deu com a formulação e implementação de políticas públicas direcionadas aos agricultores familiares, com a estruturação de mecanismos de produção-comercialização-consumo (BECKER; ANJOS, 2010), por meio de programas, tais como o Programa de Aquisição de Alimentos da Agricultura Familiar (PAA), Programa Nacional de Alimentação Escolar (PNAE) e Programa Paulista da Agricultura de Interesse Social (PPAIS).

Diferentemente do que ocorreu na Europa e mesmo nos Estados Unidos, no Brasil as condições para reprodução dos small farmer, camponeses, ou agricultores familiares não se estruturaram como âncoras na política agrícola (DELGADO, 2005). Ao contrário, o que aqui se observou foi uma solução na perspectiva do modelo da via Prussiana, ou seja, a aliança da grande propriedade com o grande capital que a política agrícola brasileira sempre atendeu. Mesmo com a pressão dos movimentos sociais e algumas conquistas no campo das políticas públicas como a criação do Programa Nacional de Fortalecimento da Agricultura Familiar (PRONAF) esse processo nunca foi revertido, pois esta política, em particular, é carente de instrumentos de garantia de comercialização da produção, diferentemente dos principais programas de crédito rural elaborados para dar suporte à produção.

No caso de políticas de apoio e garantia à comercialização, estas buscam contribuir na construção de um ambiente favorável no funcionamento dos circuitos mercantis. E no caso do Brasil, com a orientação dos mercados institucionais para a agricultura familiar tem-se também a preocupação com a construção da segurança alimentar e nutricional do país, proposta pela Lei n ${ }^{\circ}$. 11.346/2006 (BRASIL, 2006).

\section{POLÍTICAS PÚBLICAS DE AQUISIÇÃO DE ALIMENTOS DA AGRICULTURA FAMI- LIAR BRASILEIRA}

O PAA foi criado pela Lei $\mathrm{n}^{\circ}$. 10.696/2003 (BRASIL, 2003), como parte da política pública recente de fortalecimento da agricultura familiar. Trata-se da primeira política pública brasileira de aquisição de alimentos direcionada especificamente ao segmento da agricultura familiar. Para Grisa et al. (2011) a criação do PAA é resultante da confluência de dois debates importantes da década de 1990 no Brasil. Um relativo ao combate à fome e à garantia da segurança alimentar e nutricional da população brasileira e o outro centrado no reconhecimento da agricultura familiar como categoria social.

Muller (2007) comenta que o PAA tem como principal objetivo a comercialização dos produtos da agricultura familiar. De fato, o programa articula a produção da agricultura familiar com os mercados institucionais e princípios da segurança alimentar, sendo que os alimentos adquiridos dos agricultores familiares pelo programa são destinados a: (a) pessoas em situação de vulnerabilidade social; (b) rede de equipamentos públicos de alimentação e nutrição; (c) instituições socioassistenciais e escolas da rede pública ou filantrópica de ensino; (d) formação de estoques públicos de alimentos; ou (e) outras finalidades definidas pelo Grupo Gestor do Programa $(\mathrm{SCH}-$ MITT; GRISA, 2013).

Atualmente, o PAA está organizado em seis modalidades: I - Compra com Doação Si-

1 São consideradas como políticas públicas as diretrizes e os princípios norteadores da ação do poder público que estão explicitadas, sistematizadas ou formuladas em documentos (leis e programas) que orientam ações que normalmente envolvem recursos públicos (TEIXEIRA, 2002). Já Souza (2006), considera como política pública aquilo que em democracias estáveis, o governo faz ou deixa de fazer. 
multânea; II - Compra Direta; III - Incentivo à Produção e ao Consumo de Leite; IV - Apoio à Formação de Estoques; V - Compra Institucional e VI - Aquisição de Sementes. O programa integra o Sistema Nacional de Segurança Alimentar e Nutricional - SISAN, instituído pela Lei $n^{\circ} .11 .346 / 2006$, e pretende, entre outros objetivos: promover inclusão econômica e social da agricultura familiar; acesso à alimentação à populações em situação de insegurança alimentar e das unidades escolares; formar estoques públicos, de cooperativas e demais organizações da agricultura familiar; fortalecer circuitos locais e redes de comercialização, especialmente de produtos orgânicos e agroecológicos e, por conseguinte, favorecer hábitos saudáveis de alimentação e a organização social dos agricultores familiares (BRASIL, 2012).

Ou seja, o PAA atende a finalidades específicas ao estimular a formação e fortalecimento de redes de produção-consumo locais visando populações carentes e aparelhos públicos como escolas, hospitais, presídios entre outros e, ao mesmo tempo, permite regulação dos preços por meio das compras diretas e da formação de estoques, verticalização da produção e agregação de valor (SCHMITT; GRISA, 2013).

$\mathrm{O}$ ingresso nos mercados institucionais, particularmente via PAA, promoveu o acesso dos agricultores familiares a um mercado próximo, capaz de absorver grande diversidade de produtos e de se ajustar, pelo menos em certa medida, às variações sazonais (SCHIMITT; GUIMARÃES, 2008). Segundo estes autores, na prática, a grande variedade de produtos presente nos cardápios das escolas, entidades assistenciais e demais programas sociais favorece a diversificação dos sistemas produtivos da agricultura familiar, proporcionando também a valorização de gêneros muitas vezes negligenciados nos mercados convencionais.

Schimitt e Guimarães (2008) relatam que o PAA possui flexibilidade na sua execução, com possíveis ajustes entre a oferta e a demanda de alimentos em seus projetos. Percebe-se tal situação mediante acerto entre as organizações dos produtores (beneficiários fornecedores) e as instituições receptoras (be- neficiários consumidores) que por meio do diálogo, possibilita margem de manobra para a adaptação dos cardápios à sazonalidade da produção agrícola, bem como a introdução de produtos regionais. O processamento de alguns produtos como, por exemplo, de doces e sucos, é uma demonstração trazida pelas autoras, do ajuste da oferta de produtos às variações sazonais da produção agrícola aos projetos do programa.

Em termos quantitativos, Plein e Filippin (2012) esclarecem que no ano de 2011, foram aplicados no PAA R\$ 667,32 milhões, beneficiando 160.011 agricultores familiares, com aquisição de 517.921 toneladas de alimentos destinados a 20.178.462 pessoas (MDS, 2014). Para o ano de 2014, os limites individuais de recursos disponibilizados pelo PAA variaram de $\mathrm{R} \$ 6.000,00$ a $\mathrm{R} \$ 20.000,00$ por DAP/ano (MDS, 2014), porém, neste mesmo ano foram aplicados somente $\mathrm{R} \$ 565,68$ milhões no Programa (MDS, 2016), um valor significativamente menor que para o ano de 2011. Essa redução de valores aplicados é fruto, em certa medida, de algumas transformações pelas quais o Programa vem passando (Termo de Adesão, Chamada Pública), e também, especialmente, em virtude de um maior controle e fiscalização necessários e fundamentais ao funcionamento de políticas públicas, após operações policiais como a "Operação Agro-Fantasma”, que teve o PAA como objeto, deflagrada no estado do Paraná em 2013 com o objetivo de combater esquemas de desvio de recursos públicos (PF, 2016).

A alimentação escolar também merece destaque entre as políticas públicas de aquisição de alimentos, tanto pela duração, visto que no ano de 2014 completou sessenta anos de existência, quanto pela magnitude, visto ser considerado no cenário mundial um dos maiores programas de atendimento universal na área de educação (SANTOS et al., 2012; BELIK; CHAIM, 2009).

A partir da Lei no ${ }^{\circ}$ 11.947/2009 (BRASIL, 2009) o PNAE, também passa a estabelecer um elo institucional entre a alimentação oferecida nas escolas públicas e a agricultura 
familiar local ou regional (SCHMITT; GRISA, 2013). Com isso podemos dizer que a referida lei considera concomitantemente o fortalecimento da agricultura familiar e a contribuição desta para com o desenvolvimento social e econômico local (MEC, 2013).

É importante destacar uma ordem de prioridade nas aquisições do PNAE: grupos formais em nível local detentores da Declaração de Aptidão ao Pronaf (DAP Jurídica) que considera agricultores familiares nos requisitos da Lei 11.326/2006 (BRASIL, 2006); fornecedores individuais (DAP Física); e gêneros alimentícios certificados como orgânicos ou agroecológicos. O programa deve conseguir atender às demandas do cardápio da alimentação escolar, oferecendo, no mínimo, três porções de frutas e hortaliças por semana $(200 \mathrm{~g} /$ aluno/semana) nas refeições ofertadas. A alimentação escolar deve priorizar gêneros alimentícios básicos, de modo a respeitar as referências nutricionais, os hábitos alimentares, a cultura alimentar da localidade e pautar-se na sustentabilidade, sazonalidade e diversificação agrícola da região, bem como na alimentação saudável e adequada. No caso de oferta de bebidas à base de frutas, estas não substituem a obrigatoriedade da oferta de frutas in natura e a composição destas bebidas deverá seguir as normativas do Ministério da Agricultura, Pecuária e Abastecimento (MAPA) (MEC, 2013).

Os alimentos adquiridos via PNAE devem atender às exigências do controle de qualidade estabelecidas pelas normas que regulamentam a matéria; a exigência quanto ao mínimo de 30\% do uso dos recursos do FNDE na aquisição de gêneros alimentícios da agricultura familiar poderá ser dispensada quando da presença de: a) impossibilidade de emissão do documento fiscal correspondente; b) inviabilidade de fornecimento regular e constante dos gêneros alimentícios; c) condições higiênicos-sanitárias dos alimentos serem inadequadas (BRASIL, 2009).

Em termos quantitativos, o valor disponibilizado no ano de 2011 para o forneci- mento da alimentação escolar aos 44 milhões de beneficiários diários do PNAE foi de aproximadamente R\$ 3 bilhões, ou seja, o mercado reservado exclusivamente para a agricultura familiar alcançou o volume de aproximadamente R\$ 1 bilhão, uma vez que, no mínimo $30 \%$ dos recursos totais repassados pelo Fundo Nacional de Desenvolvimento da Educação (FNDE) devem ser utilizados na aquisição de gêneros alimentícios diretamente da agricultura familiar e do empreendedor familiar rural ou de suas organizações (BRASIL, 2009). No referido programa, o limite individual de venda do agricultor familiar e do empreendedor familiar rural para a alimentação escolar deverá respeitar o valor máximo de $\mathrm{R} \$ 20.000,00$ (vinte mil reais) por DAP/ano (MEC, 2013). Apesar de representar uma conquista, o mercado do PNAE impõe também um grande desafio para as organizações produtivas da agricultura familiar (MOREIRA, 2013).

O PPAIS, criado pela Lei $n^{\circ}$. 14.591/2011 (SÃO PAULO, 2011), é uma ação do Governo do Estado de São Paulo que visa: a) fomentar a organização e modernização da produção e melhorar o escoamento dos produtos da agricultura familiar; b) estimular a produção da agricultura familiar, contribuindo para a prática de preços adequados e ampliação do mercado de consumo; c) favorecer a aquisição dos produtos provenientes da agricultura familiar nas compras realizadas pelos órgãos públicos estaduais. Este Programa faz com que o Estado de São Paulo se torne também comprador dos produtos da agricultura familiar para a produção de refeições em órgãos como hospitais públicos, presídios, escolas públicas, instituições de amparo social e outras entidades (SÃO PAULO, 2011).

O PPAIS segue os moldes do PNAE, em que no mínimo 30\% das verbas estaduais destinadas à compra direta de alimentos têm de adquirir produtos oriundos da agricultura familiar, in natura e manufaturados, até um limite anual, que tem seu valor revisado anualmente $^{2}$. Tal percentual, também poderá ser 
dispensado em caso de: i) não atendimento das chamadas públicas pelos agricultores ou suas organizações; ii) impossibilidade de emissão do documento fiscal correspondente pelo agricultor ou sua organização; iii) inviabilidade de fornecimento regular e constante dos gêneros alimentícios por parte dos agricultores ou suas organizações; iv) incidência de pragas ou acidente natural que resulte na perda da produção dos agricultores familiares; v) condições higiênico-sanitárias inadequadas (SÃO PAULO, 2011).

2. ASPECTOS INOVATIVOS EM POLÍTICAS PÚBLICAS DE AQUISIÇÃO DE ALIMENTOS

A palavra inovação relaciona-se ao ato de inovar, ao ato de fazer algo novo (FUCK; VILHA, 2012). Para os autores, Joseph Alois Schumpeter define que o conceito de inovação seria representado pelos "novos bens de consumo, dos novos métodos de produção ou transporte, dos novos mercados, das novas formas de organização industrial". Por sua vez, Moricochi e Gonçalves (1994) consideram que, para o autor supracitado, "inovação" significa "fazer as coisas diferentemente no reino da vida econômica”.

O próprio Schumpeter (1997 [1911]) salienta a importância de arranjos inovativos para a rentabilidade das organizações, destacando, entre as formas de inovar, aquelas classificadas como "novas combinações", representadas por: “1) Introdução de um novo bem - ou seja, um bem com que os consumidores ainda não estão familiarizados - ou de uma nova qualidade de um bem; 2) Introdução de um novo método de produção, ou seja, um método que ainda não tenha sido testado pela experiência no ramo próprio da indústria de transformação, que de modo algum precisa ser baseada numa descoberta cientificamente nova, e pode consistir também em nova maneira de manejar comercialmente uma mercadoria; 3) Abertura de um novo mercado, ou seja, de um mercado em que o ramo particular da indústria de transformação do país em questão não tenha ainda entrado, quer esse mercado tenha existido antes, quer não; 4) Conquista de uma nova fonte de oferta de matérias-primas ou de bens semimanufaturados, mais uma vez independentemente do fato de que essa fonte já exista ou que tenha sido criada; 5) Estabelecimento de uma nova organização de qualquer indústria, como a criação de uma posição de monopólio (por exemplo, pela trustificação) ou a fragmentação de uma posição de monopólio"” (SCHUMPETER, 1997 [1911]. p. 76).

Santini et al. (2006) ressalta que a extensão de uma mudança técnica pode ser de caráter radical (refere-se a eventos descontínuos em que a mudança técnica e organizacional representam novas bases de produção, distintas das exploradas até então, com avanços do conhecimento) ou incremental (referese a melhorias nos produtos, processos, organizações e sistemas de produção existentes, ou seja, relaciona-se à demanda do mercado e às experiências dos usuários, como num processo contínuo de melhoramentos).

A teoria evolucionária neo-schumpeteriana, ao enfatizar a natureza endógena do processo inovativos, acrescenta reflexão sobre dois aspectos fundamentais: a) que a inovação se desenvolve por um processo evolucionário, interativo entre atores e entre diferentes estágios de desenvolvimento; e b) que o conhecimento e o aprendizado desempenham um importante papel em economias desenvolvidas.

É no olhar sobre esses fatores de construção de conhecimento que residem os principais aspectos inovativos dos arranjos institucionais que, não somente como fator que ordena e regula o comportamento dos agentes econômicos, mas que, inclusive, interfere na forma: i) como esses agentes percebem a realidade; ii) como enxergam as transformações em curso e iii) como aprendem (SERI, 2003; FELIPE, 2008).

Dentre os critérios que classificam os agricultores como familiares, dois se destacam: a) a direção do estabelecimento devendo ser exercida pelo produtor, e b) o trabalho familiar superior ao contratado. Para estes esta- 
belecimentos, já é amplamente discutido que, pela história dos grupos de produtores, a tradição, herança cultural e a busca por autossuficiência alimentar se conjugam como estratégias produtivas, sobremaneira com a diversificação de produção. Assim, diversificação e pequena escala produtiva explicam a composição da produção da agricultura familiar. Ocorre que tal perfil produtivo se faz acompanhar de significativas restrições para inserção nos equipamentos de comercialização tradicionais. Buainain (2006) identifica estas restrições, e indica o acesso precário aos mercados como uma importante restrição ao desenvolvimento deste segmento produtivo. Basicamente a diversidade produtiva é acompanhada de pequenos excedentes comercializáveis, e quando estes excedentes tornam-se disponíveis para comercialização os pequenos volumes, apresentam: a) falta de regularidade na oferta e b) falta de expressão de um padrão de qualidade extrínseca (como: tamanho, calibre e cor). Esses fatores se constituem nas principais razões que impedem o acesso regular dos produtores aos mercados varejistas.

Nesse sentido, o conjunto dos programas (PAA, PNAE e PPAIS) inovam por criarem uma demanda regular na via institucional para esse excedente de produção comercializável, flexibilizando as exigências de qualidade extrínsecas mencionadas, embora mantendo o atributo de frescor como um fator de qualidade a ser destacado. Os programas têm como objetivos que os produtores familiares pouco inseridos aos mercados venham a utilizar os mercados institucionais como canais de comercialização que oferecem garantias de demanda certa para o excedente de produção.

Entretanto, a operacionalização dos programas com a garantia institucional de compra deve ser limitada e por tempo determinado, embora indefinido. Ou seja, se reconhece que a inserção regular nos mercados formais impõe exigências, sendo que a habilidade para tal requer tempo e construção de conhecimento para aumento de escala e aprendizagem, visando ajustar os processos de produção e beneficiamento dos produtos para in- serção nos canais de comercialização regulares, não institucionais.

Assim, incentivar os processos de aprendizagem pode ser considerado o grande valor inovativo embutido na estrutura institucional dos programas. Assim, concordamos com Arnaldo Campos, Secretário Nacional de Segurança Alimentar e Nutricional do MDS, ao afirmar que o PAA possui caráter pedagógico, pois “o PAA ajudou a preparar os agricultores familiares para o mercado. Houve aprendizagem em relação ao planejamento da produção, da regularidade de fornecimento, de formalização, de qualidade, de preços, entre outros aspectos" (MDS, 2016).

A teoria evolucionária neo-schumpteriana destaca em seu referencial teórico o valor das informações externas e a interação com o ambiente na construção de processos de aprendizagem que podem propiciar o desenvolvimento de inovações. Nelson e Winter (1982) destacam a organização das rotinas, a qual é entendida como um processo de organização e processamento interno das atividades, relevante para a reposição dos conhecimentos de ordem produtiva e tecnológica. Para os autores, partes dessas rotinas são desenvolvidas em um processo de interação com o ambiente concorrencial nos mercados, e pela introdução de inovações.

Os programas institucionais de compras de alimentos possibilitam também a criação de um relacionamento que possibilita a aprendizagem partilhada, pois a frequência de produção para entrega aos programas institucionais é capaz de desencadear processos de aprendizagem partilhada em um processo de construção de capital social, dado que esse processo é acompanhado pelo desenvolvimento de laços sociais mais estreitos entre os produtores, o que favorece a interação também com outros agentes de comercialização presentes nos mercados locais.

Também Theodore Schutz em sua contribuição seminal, anterior aos autores supracitados, destacou a importância da construção das estruturas macroinstitucionais na promoção de educação e o capital humano na agri- 
cultura para que os produtores pudessem romper as barreiras do tradicionalismo e ingressar em um modelo mais factível de geração de riqueza (SCHUTZ, 1964). Embora destacasse os fatores promotores da ruptura do tradicionalismo na agricultura rumo a um padrão tecnológico que permite ganhos de escala em um padrão produtivo definido como produtivista que não se aplica à produção familiar, o autor ressalta que os pequenos agricultores (no caso, designados como "tradicionais") alocam eficientemente seus recursos produtivos e que a baixa rentabilidade da agricultura fundavase não em problemas de racionalidade alocativa, mas sim na incapacidade de se criar renda a partir de fatores cujas produtividades marginais eram visivelmente decrescentes (SALLESFILHO, 2005). Estas considerações serviram para que países como o Brasil desenvolvessem suas bases para modernizar tecnologicamente o setor agropecuário, entretanto, neste caso, não foram consideradas estratégias para ao mesmo tempo se promover a conquista de segurança alimentar e inclusão dos pequenos produtores aos mercados formais, juntamente com o aumento da oferta agrícola.

Desta forma, a inovação deve ser também percebida como um processo social (EDQUIST; JOHNSON, 1997), passível de formular soluções coletivas em sintonia com os arranjos institucionais capazes de desencadear processos de aprendizagem. Para Kim (1993), aprendizado é um processo de respostas aos estímulos e mudanças no ambiente externo.

Finalmente, seguindo esses princípios das teorias de inovação, percebe-se que estas também fizeram parte dos contextos das políticas públicas de aquisição de alimentos da agricultura familiar, tais como no PAA, PNAE e PPAIS.

3. INOVAÇÕES PRESENTES NAS POLÍTICAS PÚBLICAS DE AQUISIÇÃO DE ALIMENTOS NO BRASIL

O PAA tem como finalidade fortalecer circuitos locais, regionais e redes de co- mercialização e no PNAE tem-se o elo institucional entre a alimentação oferecida nas escolas públicas e a agricultura familiar local ou regional, pois "a aquisição dos gêneros alimentícios, no âmbito do PNAE, deverá obedecer ao cardápio planejado pelo nutricionista e será realizada, sempre que possível, no mesmo ente federativo em que se localizam as escolas" (BRASIL, 2009), com uma cultura alimentar da localidade, em que "favoreçam os hábitos alimentares regionais e culturais saudáveis" (MEC, 2013). Ou seja, do ponto de vista local, os dois programas possuem o potencial de promover: 1) desenvolvimento econômico; 2) redução das desigualdades; 3) segurança alimentar e nutricional (BELIK; DOMENE, 2012).

Neste sentido, os objetivos de longo prazo de uma política pública de desenvolvimento com perspectivas locais estariam sendo atingidos. Relacionar-se-iam ao investimento, ao desenvolvimento, à estruturação do setor agrícola e à melhoria na distribuição de renda, com ações de estímulo à produção e à produtividade e de redução da dependência externa (BUAINAIN, 1999).

Lima e Corrêa (2013) comentam que o PAA pode construir novos mercados para o caso de agricultores assentados, permitindo a organização da matriz produtiva destes, com geração de renda e trabalho. A garantia de compra dos produtos dos assentados, com a implementação do PAA em assentamentos de reforma agrária, pode tornar uma estratégia interessante para a efetivação da reforma agrária no país, desenvolvendo os assentamentos e enfrentando a pobreza no meio rural. Plínio de Arruda Sampaio, por exemplo, considera a reforma agrária como elemento estratégico de um novo modelo de desenvolvimento econômico para o Brasil (ABRAMOVAY, 1992).

Outrainovação presente noPAA ePNAE é tratada no artigo 19 da Lei no ${ }^{\circ} 10.696 / 2003$ e no artigo 14 da Lei ${ }^{\circ} 11.947 / 2009$, que deixam em segundo plano a lógica do menor preço para as compras dos agricultores familiares. Por meio da dispensa de licitação, pagamentos 
a preços correntes e garantia de comercialização trazem para o primeiro plano uma política pública de estímulo ao desenvolvimento da agricultura familiar. No entanto deve-se considerar que a partir do ano de 2014, no PAA se exige o procedimento administrativo de chamada pública, voltado à seleção da melhor proposta para aquisição de produtos de beneficiários fornecedores e organizações fornecedoras (BRASIL, 2014). No PPAIS, pelo decreto $\mathrm{n}^{\mathrm{o}} 57.755 / 2012$, em seu artigo 11 , o edital de chamada pública deve "conter o preço a ser pago pela aquisição” (SÃO PAULO, 2014).

Conforme Reinach et al. (2012) o sistema de compras públicas brasileiro até recentemente operava somente com base na Lei $\mathrm{n}^{\mathrm{O}}$ 8.666/1993 (Lei de Licitações e Contratos), que tem como princípio a compra de um produto ou serviço pagando-se o menor preço possível. O fundamento de tal lógica baseiase na visão da escassez de recursos públicos e, principalmente, no princípio de eficiência que se entende, vulgarmente, como ter o maior ganho pelo menor preço. Com o PAA, PNAE e PPAIS tal situação foi alterada, no entanto a aplicação das referidas legislações não deixam de serem complexas.

Ainda segundo os autores, o desafio a ser enfrentado pela legislação dos programas consiste em promover a aproximação da oferta e da demanda, a fim de que haja a venda da produção dos empreendimentos da agricultura familiar para o fornecimento aos programas de alimentação mantidos e operados por municípios e também para as entidades estaduais e federais. No caso do PNAE, Schimitt e Guimarães (2008) consideram que a dispensa de licitação para a compra de produtos agropecuários representou um importante avanço abrindo perspectivas efetivas para que agricultores familiares e suas organizações econômicas rompam com a quase exclusividade das empresas privadas no acesso ao mercado da merenda escolar.

A questão de oferta e demanda de produtos agrícolas pelos agricultores familiares no PAA e PNAE são distintas de outras modalidades de compras públicas. No PNAE, por exemplo, “os cardápios da alimentação escolar deverão ser elaborados pelo nutricionista responsável com utilização de gêneros alimentícios básicos, respeitando-se as referências nutricionais, os hábitos alimentares, a cultura e a tradição alimentar da localidade, pautando-se na sustentabilidade e diversificação agrícola da região, na alimentação saudável e adequada” (BRASIL, 2009).

Já no caso do PAA, a proposta do projeto leva em consideração se a lista de produtos oferecidos respeita as condições de alimentos saudáveis e diversificados (MDS, 2014). No PPAIS, percebe-se que o mesmo é pouco inovador quanto a este aspecto, visto que o edital de chamada exige a "descrição do(s) produto(s) a ser(em) adquirido(s) e respectiva quantidade, de forma clara, precisa e sucinta" (SÃO PAULO, 2012) e dispensa a exigência de 30\% dos produtos da agricultura familiar, quando tem-se "inviabilidade de fornecimento regular e constante dos gêneros alimentícios por parte dos agricultores ou suas organizações" (SÃO PAULO, 2011).

Seguindo o conceito de Schumpeter (1997), processos inovativos guardam uma dimensão qualitativa. No contexto da agricultura familiar pelo PAA, PNAE e PPAIS, se percebe o caráter inovador com a possibilidade de comercialização de produtos agrícolas in natura e também de produtos agrícolas manufaturados/industrializados pelos agricultores. No PAA fica visível tal situação quando o programa busca "incentivar a agricultura familiar, promovendo a sua inclusão econômica e social, com fomento à produção com sustentabilidade, ao processamento, à industrialização de alimentos e à geração de renda" (BRASIL, 2012). No PNAE “a oferta de doces e/ ou preparações doces fica limitada a duas porções por semana, equivalente a $110 \mathrm{kcal} /$ porção” (MEC, 2013). No PPAIS, “a consecução dos objetivos destinados à aquisição de gêneros alimentícios, "in natura" ou manufaturados, para hospitais públicos, presídios, escolas públicas, instituições de amparo social e outras entidades” (São Paulo, 2011). 
A partir deste tipo de política pública pode-se alcançar o que Medeiros e Marques (2013) afirmam sobre o papel da agroindustrialização familiar quanto à minimização da pobreza, do desemprego, do êxodo rural, da exclusão da mulher e dos jovens da vida econômica e das ações comunitárias locais. Porém, para isso, a agroindustrialização familiar depende de vários fatores técnicos e gerenciais para alcançar os sucessos produtivos e comerciais, inclusive acesso a um mercado consumidor de tamanho e volume de demanda adequados (ZUIN et al., 2013), casos possibilitados pelo PAA, PNAE e PPAIS.

Maluf (2004), por exemplo, lembra que a elaboração ou ao processamento de alimentos em unidades de tipo artesanal (pequenas agroindústrias e indústrias caseiras) ou em agroindústrias de pequena e média escalas, devem continuar incorporando os requisitos de qualidade dos produtos e respeitar regularidade da produção e os programas (PAA, PNAE e PPAIS) são exigentes no quesito qualidade de produtos, principalmente nas condições higiênico-sanitárias adequadas.

A produção orgânica e agroecológica é uma inovação que vem a calhar com as políticas públicas de aquisição de alimentos da agricultura familiar, visto que os programas incentivam tal produção como percebe-se no caso do PAA, "promover e valorizar a biodiversidade e a produção orgânica e agroecológica de alimentos" (BRASIL, 2012) e no PNAE, "estimulem e promovam a utilização de produtos orgânicos e/ou agroecológicos e da sociobiodiversidade" (MEC, 2013). Ambos ainda possibilitam o acréscimo de 30\% aos preços de referência para os alimentos produzidos de modo agroecológico e/ou orgânico. No PPAIS, não se identifica o incentivo à produção orgânica e agroecológica.

A proposta de aquisição de produtos orgânicos e/ou agroecológicos por parte do Estado provoca também uma reflexão acerca do papel deste na reestruturação dos circuitos de produção, distribuição e consumo de alimentos com base em princípios de justiça so- cial e sustentabilidade ambiental (SCHIMITT; GUIMARÃES, 2008).

Finalmente, deve ser mencionado como inovador na relação entre agricultura familiar e políticas públicas de aquisição de alimentos a organização social das famílias. No PAA, tem-se como finalidade deste "estimular o cooperativismo e o associativismo" (BRASIL, 2012), enquanto no PNAE, têm-se que "do total dos recursos financeiros repassados pelo FNDE, no âmbito do PNAE, no mínimo 30\% (trinta por cento) deverão ser utilizados na aquisição de gêneros alimentícios diretamente da agricultura familiar e do empreendedor familiar rural ou de suas organizações, priorizando-se os assentamentos da reforma agrária, as comunidades tradicionais indígenas e comunidades quilombolas" (BRASIL, 2009). O PPAIS tem como objetivo "fomentar a organização e modernização da produção e melhorar o escoamento dos produtos da agricultura familiar", onde "a aquisição de gêneros alimentícios [...] poderá ser feita até o valor máximo de R\$ 12.000,00 (doze mil reais) por ano, por agricultor, salvo quando se tratar de aquisição efetuada de associação ou cooperativa, hipótese em que esse valor deverá ser multiplicado pelo número de seus integrantes" (SÃO PAULO, 2011). Ou seja, os três programas se propõem a fortalecer os circuitos locais, regionais e redes de comercialização, oferecendo experiências concretas (estímulo) de produção para comercialização em bases coletivas, favorecendo construções de capital social.

Schimitt e Guimarães (2008) afirmam que o PAA tem contribuído para fortalecer a construção de redes de produção e consumo que envolvem um amplo leque de organizações sociais e que isso não se limita apenas ao acesso dos mercados, pois já incorporam também uma série de objetivos relacionados à promoção da segurança alimentar e nutricional, no entanto esforços organizativos potencializam sucesso aos empreendimentos familiares.

Gonçalves (2014), por exemplo, comenta que no sudoeste de São Paulo, a ori- 
gem recente de cooperativas e associações, em quase sua totalidade tem como fator principal a possibilidade de acesso aos programas de compras governamentais. Por um lado, as políticas públicas de aquisição de alimentos estão induzindo ao associativismo e cooperativismo e, por outro, tal situação pode ser preocupante na inexistência do desenvolvimento de outros canais de comercialização criandose uma dependência não desejada. Para Delgado (2005) com a organização de agricultores, em bases associativas e cooperativas, é possível viabilizar massivamente a comercialização de excedentes e aproveitar os ganhos de escala que a economia dos mercados oferece.

O estímulo à organização social das famílias, presente na relação entre agricultura familiar e as políticas públicas em consideração, pode induzir a promoção de processos de aprendizagem coletiva, como resposta ao estímulo oferecido institucionalmente, na concepção de Kim (1993), pela presença de canais de comercialização definidos e estáveis.

\section{CONSIDERAÇÕES FINAIS}

Percebe-se que a partir das aquisições de alimentos pelo Estado dos agricultores familiares desencadeiam-se processos inovativos significativos advindos de políticas públicas, tais como: a dispensa de licitação ou a chamada pública; a consideração do mercado e o desenvolvimento local e regional; flexibilizam-se as exigências de atributos relacionadas à qualidade extrínseca dos produtos normalmente exigidos nos mercados varejistas tradicionais, como padrão, uniformidade, quantidade e regularidade de fornecimento; a possibilidade de aquisição de produtos agrícolas tanto in natura como de produtos que sofreram algum tipo de processamento e manufatura; a organização formal ou informal dos agricultores familiares por meio associações e/ou cooperativas; e pela valorização e possibilidade de aquisição de produtos produzidos em manejo orgânico e agroecológico. Assim sendo, as inovações trazidas pelas políticas públicas de aquisição de alimentos dos agricultores fami- liares foram de: produto, processo, mercado e organizacional.

Dentre os três programas que representam novos formatos de mercados institucionais, as inovações de modelo de negócios geradas possibilitam maior alcance relativo para o PAA, exigindo alguns ajustes para maior eficácia dos outros dois programas.

Recebido em: 02/05/2016

Aprovado em: 11/08/2016

\section{REFERÊNCIAS}

ABRAMOVAY, Ricardo. Paradigmas do $\mathrm{Ca}$ pitalismo Agrário em Questão. São Paulo Rio de Janeiro - Campinas. Editora Hucitec, ANPOCS, Editora da Unicamp, 1992.

BECKER, Cláudio.; ANJOS, Flávio Sacco dos. Segurança alimentar e desenvolvimento rural: limites e possibilidades de aquisição de alimentos da agricultura familiar, em municípios do sul gaúcho. Segurança Alimentare Nutricional, Campinas, v. 17, n. 1, p. 61-72, 2010.

BELIK, Walter; CHAIM, Nuria Abrahão. O programa nacional de alimentação escolar e a gestão municipal: eficiência administrativa, controle social e desenvolvimento local. Revista Nutrição, Campinas, v. 22, n. 5, Sept./ Oct. 2009.

BELIK, Walter; DOMENE, Semíramis Martins Álvares. Experiências de programas combinados de alimentação escolar e desenvolvimento local em São Paulo-Brasil. Agroalimentaria. v. 18, n. 34; enero-junio 2012. p. 57-72.

BRASIL. Decreto $n^{\circ}$ 8.293, de 12 de agosto de 2014. Altera o Decreto $\mathrm{n}^{\mathrm{O}} 7.775$, de 4 de julho de 2012, que dispõe sobre o Programa de Aquisição de Alimentos. Diário Oficial da União, Brasília, DF, 13 de agosto de 2014. Disponível em: http://www.planalto. 
gov.br/ccivil_03/_ato2011-2014/2014/Decreto/D8293.htm. Acesso em: 09 fev. 2016.

BRASIL. Decreto $n^{\circ} 7.775$, de 4 de Julho de 2012. Regulamenta o art. 19 da Lei $\mathrm{n}^{\circ}$ 10.696, de 2 de Julho de 2003, que institui o Programa de Aquisição de Alimentos, e o Capítulo III da Lei $\mathrm{n}^{\mathrm{o}}$ 12.512, de 14 de Outubro de 2011, e dá outras Providências. Diário Oficial da União, Brasília, DF, 4 de Julho de 2012. Disponível em: https://www.planalto. gov.br/ccivil_03/_ato2011-2014/2012/decreto/d7775.htm. Acesso em: 22 jan. 2015.

BRASIL. Lei $n^{\circ}$ 11.947, de 16 de junho de 2009. Dispõe sobre o atendimento da alimentação escolar e do Programa Dinheiro Direto na Escola aos alunos da educação básica- altera as Leis nos 10.880, de 9 de junho de 2004, 11.273, de 6 de fevereiro de 2006, 11.507, de 20 de julho de 2007- revoga dispositivos da Medida Provisória no 2.17836, de 24 de agosto de 2001, e a Lei $n^{\circ} 8.913$, de 12 de julho de 1994- e dá outras providências. Diário Oficial da União, Brasília, DF, 16 de junho de 2009. Disponível em: http://www.planalto.gov.br/ccivil_03/_ato2007-2010/2009/lei/ 111947.htm. Acesso em: 22 jan. 2015.

BRASIL. Lei $n^{\circ} 11.346$, de 15 de setembro de 2006. Cria o Sistema Nacional de Segurança Alimentar e Nutricional - SISAN com vistas em assegurar o direito humano à alimentação adequada e dá outras providências. Diário Oficial da União, Brasília, DF, 18 de setembro de 2006. Disponível em: http://www.planalto.gov.br/ccivil_03/_ato2004-2006/2006/lei/ 111346.htm Acesso em: 09 fev. 2016.

BRASIL. Lei $n^{\circ}$ 11.326, de 24 de Julho de 2006. Estabelece as diretrizes para a formulação da Política Nacional da Agricultura Familiar e Empreendimentos Familiares Rurais. Diário Oficial da União, Brasília, DF, 25 de Julho de 2006. Disponível em: http://www.planalto.gov.br/ccivil_03/_ato2004-2006/2006/ lei/l11326.htm. Acesso em: 21 fev. 2016.
BRASIL. Lei no 10.696, de 2 de Julho de 2003. Dispõe sobre a repactuação e o alongamento de dívidas oriundas de operações de crédito rural, e dá outras providências. Diário Oficial da União, Brasília, DF, 03 de julho de 2003. Disponível em: http://www.conab.gov. br/OlalaCMS/uploads/arquivos/ab3b7b53cfe2bb6c688ad672400a6a7a..pdf. Acesso em: 22 jan. 2015.

BUAINAIN, Antônio Márcio. Agricultura Familiar, Agroecologia e Desenvolvimento Sustentável: questões para debate. Brasília: IICA, 2006.

BUAINAIN, Antônio Márcio. Trajetória recente da política agrícola brasileira. 1999. 326 p. Tese (Doutorado em Ciências Econômicas) IE/UNICAMP.

DELGADO, Guilherme Costa. A realização da Produção na Reforma Agrária. ABRA - Reforma Agrária, v. 32, n. 1, p. 37-44, jan./jul. 2005.

EDQUIST, Charles; JOHNSON, Björ. Institutions and organizations in system of innovation. In: EDQUIST, Charles. System of innovation - technologies, institutions and organizations. London: Printer, 1997. p. 41-63.

FELIPE, Ednilson Silva. As instituições e os Neo-Schumpeterianos: a noção de aprendizado a partir do pilar cognitivo das instituições. Pesquisa e Debate, São Paulo, v. 19, 1(33), p. 15-32, jan/jun. 2008.

FUCK, Marcos Paulo; VILHA, Anapatrícia Morales. Inovação Tecnológica: da definição à ação. Contemporâneos - Revista de Artes e Humanidades. n. 9, nov.2011/abr.2012.

GONÇALVES, Daniel Bertoli. Os desafios da agricultura familiar frente aos programas de compras públicas de alimentos: um estudo sobre agricultores da região Sudoeste do Estado de São Paulo. Revista da Universidade Vale do Rio Verde, Três Corações, v. 12, n. 1, p. 604613, jan./jul. 2014. 
GRISA, Catia; SCHMITT, Cláudia Job; MATTEI, Lauro Franciso; MALUF, Renato Sergio; LEITE, Sergio Pereira. Contribuições do Programa de Aquisição de Alimentos à segurança alimentar e nutricional e à criação de mercados para a agricultura familiar. Agriculturas, v. 8, n. 3, p. 34-41, 2011.

KIM, Daniel H. The link between individual and organizational learning. Sloan Management Reviee. MIT n.1, v.35, 1993, p 37-50.

LIMA, Priscila Gualberto de; CORRÊA, Gilson César Pianta. Adquirindo alimentos da reforma agrária: o programa de aquisição de alimentos (PAA) como política de segurança alimentar nos assentamentos do Rio Grande do Sul. In: CONTERATO, Marcelo Antonio (Org.). Mercados e agricultura familiar: interfaces, conexões e conflitos. Porto Alegre: Via Sapiens, 2013. p. 167-189.

MALUF, Renato Sergio. Mercados agroalimentares e a agricultura familiar no Brasil: agregação de valor, cadeias integradas e circuitos regionais. Ensaios FEE, Porto Alegre, v. 25, n. 1, p. 299-322, abr. 2004.

Ministério do Desenvolvimento Social e Combate à Fome. Disponível em: http://mds.gov. br/area-de-imprensa/noticias/2016/janeiro/governo-federal-investiu-r-567-2-milhoes-nacompra-de-alimentos-da-agricultura-familiar. Acesso em: 22 fev. 2016.

Ministério do Desenvolvimento Social e Combate à Fome. Disponível em: http://aplicacoes. mds.gov.br/sagi/paa/2011/visi_paa_conab/pg_ principal.php. Acesso em: 20 out. 2014.

Ministério do Desenvolvimento Social e Combate à Fome. Programa de Aquisição de Alimentos: Manual Operativo: Modalidade Compra com Doação Simultânea: Operação por Meio de Termo de Adesão. Brasília, Fevereiro de 2014. Disponível em: http://www.mds.gov. $\mathrm{br} /$ segurancaalimentar/aquisicao-e-comercializacao-da-agricultura-familiar/entenda-o-paa/ manualPAA_06.03.pdf/view. Acesso em: 25 jan. 2015.
Ministério da Educação. Resolução $n^{0}$ 26, de 17 de Junho de 2013. Dispõe sobre o atendimento da alimentação escolar aos alunos da educação básica no âmbito do Programa Nacional de Alimentação Escolar - PNAE. Diário Oficial da União, Brasília-DF, 18 de junho de 2013.

MEDEIROS, Monique; MARQUES, Flávia Charão. Plantando ideias inovadoras, colhendo transformações na agricultura familiar: a produção de base ecológica e a construção social de mercados no sul do Rio Grande do Sul. In: CONTERATO, Marcelo Antonio (Org.). Mercados e agricultura familiar: interfaces, conexões e conflitos. Porto Alegre: Via Sapiens, 2013. p. 114-132.

MOREIRA, Magda Regina Santiago. Um olhar sobre a agricultura familiar, a saúde humana e o ambiente. Ciência e Cultura. v. 65, n. 3, São Paulo, July 2013.

MORICOCHI, Luiz; GONÇALVES, José Sidnei. Teoria do Desenvolvimento Econômico de Schumpeter: uma revisão crítica. Informações Econômicas, São Paulo, v.24, n.8, p. 2635. ago. 1994.

MUller, Ana Luiza. A Construção das Políticas Públicas para a Agricultura Familiar no Brasil: o caso do Programa de Aquisição de Alimentos. 2007. 128 f. Dissertação (Mestrado Desenvolvimento Rural). PGDR/UFRGS.

NELSON, Richard R.; WINTER, Sidney G. An Evolutionary Theory of Economic Change. Belknap Press/Harvard University Press: Cambridge. 1982.

Polícia Federal. Operação Agro-Fantasma combate desvios de recursos do Programa Fome Zero. Disponível em: http://www.pf. gov.br/agencia/noticias/2013/09/operacao-agro-fantasma-combate-desvios-de-recursosdo-programa-fome-zero. Acesso em: 22 fev. 2016.

PLEIN, Clério; FILIPPI, Eduardo Ernesto. O Programa Aquisição de Alimentos da Agricul- 
tura Familiar (PAA): Geração de Renda e Segurança Alimentar. Revista Faz Ciência, Francisco Beltrão, v. 15, n. 20, p.63-86. 2012.

REINACH, Sofia; CORÁ, Maria Amélia Jundurian; BONDUKI, Manuel Ruas Pereira Coelho. A Inclusão da Agricultura Familiar no Programa Nacional de Alimentação Escolar. IN: XXXVI Encontro da ANPAD. Rio de Janeiro, 22 a 26 de setembro de 2012. Disponível em: http://www.anpad.org.br/admin/ pdf/2012_APB2404.pdf. Acesso em: 20 jan. 2015 .

SÃO PAULO. Decreto $n^{\circ} 57.755$, de 24 de Janeiro de 2012. Regulamenta a Lei $\mathrm{n}^{\mathrm{O}} 14.591$, de 14 de outubro de 2011, que cria o Programa Paulista da Agricultura de Interesse Social PPAIS e dá providências correlatas. Disponível em: http://www.legislacao.sp.gov.br/ legislacao/dg280202.nsf/5fb5269ed17b47ab83256 cfb00501469/e504a091414f962d832579910045ab0e? OpenDocument. Acesso em: 22 de jan. 2015.

SÃO PAULO. Lei $n^{o}$ 14.591, de 14 de outubro de 2011. Cria o Programa Paulista da Agricultura de Interesse Social PPAIS. Disponível em: http://www.al.sp.gov.br/repositorio/legislacao/lei/2011/lei1459114.10.2011. Acesso em: 09 de dez. 2014.

SANTINI, Giuliana Aparecida; SOUZA, Roberta Castro; QUEIROZ, Timóteo Ramos; SOUZA FILHO, Hildo Meirelles de. Conceitos de Inovação. In: ZUIN, Luís Fernando Soares; QUEIROZ, Timóteo Ramos. Agronegócios: Gestão e Inovação. São Paulo: Saraiva, 2006. p. 220 - 250.

SCHMITT, Cláudia Job; GRISA, Catia. Agroecologia, Mercados e Políticas Públicas: uma análise a partir dos instrumentos de ação governamental. In: NIEDERLE, Paulo André; ALMEIDA, Luciano de; VEZZANI, Fabiane Machado. Agroecologia: práticas, mercados e políticas para uma nova agricultura. 2013. p. 215-265.
SCHIMITT, Cláudia Job; GUIMARÃES, Leonardo Alonso. O mercado institucional como instrumento para o fortalecimento da agricultura familiar de base ecológica. Agriculturas, v. 5, n. 2, p. 7-13. 2008.

SCHUMPETER, Joseph Alois. Teoria do desenvolvimento econômico: uma investigação sobre os lucros, capital, crédito, juro e o ciclo econômico. Tradução de Maria Sílvia Possas. São Paulo: Ed. Nova Cultural Ltda, 1997.

SERI, Paolo. Losing areas and shared mental models: towards a definition of the cognitive obstacles to local development. Max Planck Institute for Economic Systems Evolucionary Economics Unit, 2003.

SCHULTZ, Teodore William. A transformação da agricultura tradicional. Connecticut, EUA. 1964.

SALLES-FILHO, Sergio. Ideias Fundadoras apresentação: A transformação da Agricultura Tradicional. Revista Brasileira de Inovação. Rio de Janeiro-RJ, v. 4, n. 1, p. 1-34, Jan/Jun. 2005.

SOUZA, Celina. Políticas Públicas: uma revisão da literatura. Sociologias, Porto Alegre, Ano 8, no 16, p. 20-45. jul/dez 2006.

TEIXEIRA, Elenaldo Celso. O papel das políticas públicas no desenvolvimento local e na transformação da realidade. Salvador, Bahia: AATR, 2002.

ZUIN, Luís Fernando Soares; ZUIN, Poliana Bruno; BATTAGIN, Heloísa V.; MANRIQUE, Miguel A. Díaz; FERTE, Suzanne. Os caminhos da agroindustrialização no campo percorridos por três microempresas rurais que produzem e processam leite de cabra localizadas no estado de São Paulo. In: CONTERATO, Marcelo Antonio (Org.). Mercados e agricultura familiar: interfaces, conexões e conflitos. Porto Alegre: Via Sapiens, 2013. p. 254267. 